\title{
Consumer Perspectives on a Pericoital Contraceptive Pill In India and Uganda
}

\author{
CONTEXT: Studies suggest that women in some countries have adopted emergency contraceptive pills as a routine \\ method of family planning. This practice indicates there may be latent demand for a pericoital contraceptive pill \\ taken only when a woman has sexual intercourse, and labeled and marketed for use as a regular contraceptive \\ method.
}

METHODS: To understand the appeal and potential market for a pericoital contraceptive pill, 39 focus groups and 23 in-depth interviews were conducted with women and men in Lucknow, Uttar Pradesh, India, and Kampala, Uganda. A total of 281 individuals participated in this qualitative study.

RESULTS: In general, women embraced the idea of a female-controlled method that would be easier than taking a daily oral contraceptive pill and that could be taken either before or after sexual intercourse; in Uganda, especially, women approved of the fact that the method could be taken without a partner's knowledge. Although we do not yet know the extent of side effects for this method, women expressed some concerns about the level and nature of potential side effects.

CONCLUSIONS: The results suggest that a pericoital contraceptive pill would be well-received by consumers in both country settings. If its efficacy and side effects are acceptable, a pericoital contraceptive pill could fill a gap for female-controlled, discreet, coitus-related contraception, particularly among women who do not have sex very frequently.

International Perspectives on Sexual and Reproductive Health, 2013, 39(4):195-204. doi: 10.1363/3919513

A substantial proportion of women in developing countries with an unmet need for family planning cite infrequent sex as a reason for not practicing contraception: 6-39\% of women with unmet need in Sub-Saharan Africa and $14-35 \%$ in South and Southeast Asia. ${ }^{1}$ Notably, about one in four adolescent women aged 15-19 with unmet need report that they are not using a method because they do not have sex frequently. ${ }^{2}$ For women who have infrequent sex, an oral contraceptive pill taken only at the time of intercourse may offer advantages in terms of convenience and ease of use; because this method is discreet and female-controlled, it may appeal to other women as well.

Pericoital contraceptive pills-also referred to as "ondemand" or "real-time" contraceptives-are being considered as a way to address unmet need, especially among women who have sex no more than six times a month. There is currently no oral contraceptive pill marketed for such use. Women could take a pericoital contraceptive pill within 24 hours before or after intercourse, rather than daily. Levonorgestrel, one compound being considered as the active component in a pericoital pill, is a synthetic progestin that has been used as an active hormonal ingredient in daily birth control pills for about 40 years. It is also the key ingredient in contraceptive implants, hormone-releasing IUDs and emergency contraceptive pills. Levonorgestrel is off-patent and has a good safety profile. ${ }^{3}$
Studies from a number of countries suggest that some women are already using emergency contraception offlabel as an on-demand pill, demonstrating latent demand for a pericoital method. ${ }^{4-6}$ Women who do not have sex frequently are particularly likely to use emergency contraception as their regular method. ${ }^{4}$ Moreover, a survey of women in urban Nigeria found that those who reported having used emergency contraception had done so an average of five times in a six-month period. ${ }^{7}$ Interviews with West African women using emergency contraception as a regular method reveal a preference for the convenience of an "occasional pill" and for episodic, rather than sustained, exposure to hormones (reflecting their safety concerns about hormones that remain in the system). ${ }^{8}$ These studies show that in the absence of a coitus-related, female-controlled contraceptive method that does not interrupt sexual activity and is labeled and marketed for routine use, women have adapted an existing method to meet that need.

There are obvious similarities between a potential pericoital contraceptive product and currently available emergency contraception; for example, both are coitus-related methods, and the same active ingredient may be used for both. That said, a dedicated pericoital pill would be labeled and marketed for use within 24 hours before or after sex, as a routine contraceptive method. While repeat use of levonorgestrel does not pose any known health risks,
By Jane K. Cover, Jennifer Kidwell Drake, Imelda T. Kyamwanga, Eleanor Turyakira, Tanya Dargan, Edward Kumakech and Claudia Harner-Jay

Jane Cover and Jennifer Kidwell Drake are program officers, and Claudia Harner-Jay is senior commercialization officer, all at PATH, Seattle, WA, USA. Imelda Kyamwanga and Eleanor Turyakira are professors at Mbarara University of Science and Technology, Kampala, Uganda. Tanya Dargan is consultant, New Delhi, India. Edward Kumakech is program officer, PATH, Kampala, Uganda. 
emergency contraception is not currently labeled for routine use, nor for use prior to sexual intercourse. ${ }^{9}$ The appropriate or recommended coital frequency for pericoital contraceptive users will depend on the efficacy and side effects of the active ingredient; a current World Health Organization clinical trial of a pericoital pill using $1.5 \mathrm{mg}$ of levonorgestrel defines the appropriate coital frequency for study participants as six or fewer times a month.

To understand better the appeal and potential market for a pericoital contraceptive pill, PATH conducted a qualitative study of the perceptions of potential consumers in Lucknow, Uttar Pradesh, India, and Kampala, Uganda. PATH assessed the general appeal of the method, explored anticipated patterns of use and developed potential client profiles through focus group discussions and in-depth interviews with potential consumers (241 women and 40 men).

\section{METHODS}

\section{Country Contexts}

To capture regional variation, we wanted to have study sites in both South or Southeast Asia and Sub-Saharan Africa. India was chosen because of its vibrant commercial market for oral contraceptives and emergency contraception, and because of the potential to form partnerships with local manufacturers for production and distribution. Uganda was selected due to the dominant role of the private sector in providing oral contraceptives and a recently renewed commitment to family planning by government leaders.

The study focused on urban areas under the assumption that a pericoital pill would initially be available for purchase in pharmacies and through social marketing in urban settings. This assumption is based, at least in part, on the critical role the commercial sector has played in making emergency contraception available in a variety of settings. Moreover, data on women who use emergency contraception as a primary method tend to draw on urban populations. ${ }^{4,6,7}$ We selected Lucknow and Kampala as study sites because they represented urban settings that

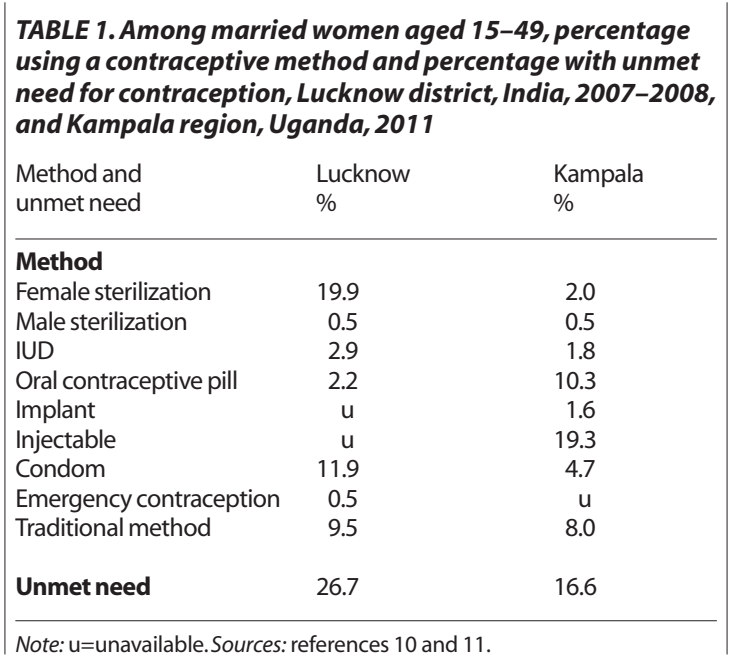

were accessible to our study teams and that have family planning infrastructure and programs that could facilitate eventual introduction of a new method.

In Lucknow district, according to the India Demographic and Health Survey (DHS), about one in four married women of reproductive age have an unmet need for family planning (Table 1). ${ }^{10}$ Sterilization, used by $20 \%$ of married women aged 15-49, dominates the contraceptive method mix, as it does for India as a whole; the next most commonly used methods are condoms (12\%) and traditional methods (10\%). Indian women wishing to space births tend to rely on methods that require male involvement (condoms, periodic abstinence and withdrawal). DHS reports do not include data on current use of emergency contraception; however, nearly 30\% of married women in Lucknow reported knowing about the method and numerous brands of emergency contraception are available in India. The strong commercial market for emergency contraception products and substantial reliance on methods that require male involvement suggest a need and demand for a female-controlled pericoital method.

In Kampala region, injectables (19\%), oral contraceptives (10\%) and traditional methods (8\%) dominate the contraceptive method mix..$^{11}$ An estimated $32 \%$ of married women in Uganda, and nearly $40 \%$ of sexually active unmarried women, know of emergency contraception, and it is available in the private sector under the brand name Postinor 2. Although emergency contraception is intended to be available by prescription only in Uganda, women are able to procure it over the counter.

Uganda's total fertility rate of about six children per woman is high, even compared with the rates in other SubSaharan African countries. ${ }^{11}$ Ugandan men desire larger families than Ugandan women do (about six children vs. five). This discord in fertility intentions may translate into challenges for women who desire to use family planning. Moreover, it may create a demand for short-term methods, like the injectable or the pericoital pill, that are femalecontrolled and can be used surreptitiously.

\section{Study Design and Analysis}

Our analysis draws on qualitative data collected through focus group discussions and in-depth interviews. We sampled participants purposefully and attempted to maximize diversity in order to gather insights on potential consumers of pericoital contraception and solicit a wide variety of viewpoints on the proposed method. Accordingly, we included married and unmarried women and men aged 1845 who were upper-middle, middle or working class and who were using modern contraceptives, traditional methods or no method. This sampling strategy draws from previous research showing that diverse characteristics can inform contraceptive use. ${ }^{12}$ In addition, we recruited young, unmarried women who either were currently attending college or had recently graduated, as well as a small sample of women who had used emergency contraception in the past, assuming that the use dynamics of another coitus- 
related oral method might provide insight on possible use of a pericoital pill.

To promote information sharing within focus group discussions, we designed each group to be homogeneous in terms of participant characteristics. In Lucknow, a team of trained recruiters identified participants through household visits and snowball sampling in a socioeconomically diverse set of neighborhoods. In Kampala, our team worked with clinic staff, community representatives, and college and other education officials in neighborhoods selected to represent a variety of socioeconomic conditions to identify potential participants. Two of the college groups were recruited through universities and one through a nursing school. In both countries, women using permanent contraception (i.e., sterilization) were excluded from participating.

The Indian field team queried married female participants about their current contraceptive use as a basis for assignment to specific focus groups; because of Ugandan women's reluctance to disclose current method use during recruitment, a mix of users and nonusers were recruited though clinics and communities and participated in focus groups together. Likewise, because it was difficult in Kampala to clearly define marriage and thus separate women by marital status, all women in any form of union and those who clearly stated that they were in a relationship but not married participated in the same focus groups. We conducted a total of 33 focus group discussions with women: 15 with women in Lucknow (a total of 116 participants) and 18 in Kampala (142 participants; Table 2).

Emergency contraception was discussed in in-depth interviews, rather than in focus groups, at the recommendation of both country teams, who felt that women might not be comfortable talking about their emergency contraception use in a group setting because of the stigma sometimes attached to this method. In Kampala, emergency contraception users were recruited through clinics and by following up with any focus group participants who mentioned having used the method. In Lucknow, we were able to recruit emergency contraception users the same way we recruited focus group participants. We conducted a total of 15 interviews with emergency contraception users (eight in Lucknow and seven in Kampala).

We recruited men because of their influence on a couple's decisions about whether to use family planning and what kind of method to use. The sample of men was designed to maximize variation in socioeconomic status, age and marital status. Men using permanent contraception were not eligible to participate. We recruited men for focus group discussions and in-depth interviews using methods similar to those described above for recruiting women in each setting. In Lucknow, we conducted six focus group discussions with a total of 30 men-three with unmarried men and three with married men. In Uganda, we used individual interviews only, because our team felt that men would not be comfortable discussing family planning in a group context. We conducted 10 in-depth interviews with men of varied marital status (single, married but living apart, or married and living together), socioeconomic status (by years of education) and age (18-29 and 30-45).

We developed the discussion and interview guides to be consistent across the two settings, but revised them to be context-appropriate following pretesting with six groups in Uganda and five in India. Specifically, we reordered the questions to improve the flow of the discussion or interview, added additional information explaining pericoital contraception and reworded some questions to improve comprehension. While some questions varied across country context, the instruments addressed the same themes regarding influences on contraceptive decision making, including knowledge of contraceptive methods, family planning decision making, perceptions about meth-

TABLE 2. Number of focus group discussions, by participant age-group, number of in-depth interviews and number of participants; all according to participant type, Lucknow, India, and Kampala, Uganda

\begin{tabular}{|c|c|c|c|c|c|c|c|c|c|c|c|c|}
\hline \multirow[t]{4}{*}{ Participant type } & \multicolumn{6}{|c|}{ Lucknow } & \multicolumn{6}{|l|}{ Kampala } \\
\hline & \multicolumn{4}{|c|}{ Focus groups } & \multirow{3}{*}{$\begin{array}{l}\text { No.of } \\
\text { interviews }\end{array}$} & \multirow{3}{*}{$\begin{array}{l}\text { No.of } \\
\text { participants }\end{array}$} & \multicolumn{4}{|c|}{ Focus groups } & \multirow{3}{*}{$\begin{array}{l}\text { No.of } \\
\text { interviews }\end{array}$} & \multirow{3}{*}{$\begin{array}{l}\text { No.of } \\
\text { participants }\end{array}$} \\
\hline & \multicolumn{3}{|c|}{ Age-group } & \multirow[t]{2}{*}{ Total } & & & \multicolumn{3}{|c|}{ Age-group } & \multirow[t]{2}{*}{ | Total } & & \\
\hline & $18-24$ & $20-29$ & $30-45$ & & & & $18-24$ & $20-29$ & $30-45$ & & & \\
\hline Married women* & na & na & na & na & na & na & na & 9 & 6 & 15 & na & 118 \\
\hline $\begin{array}{l}\text { Modern method } t \\
\text { Traditional/ }\end{array}$ & na & 3 & 3 & 6 & na & 33 & na & na & na & na & na & na \\
\hline $\begin{array}{c}\text { no methodt } \\
\text { Unmarried/college }\end{array}$ & na & 3 & 3 & 6 & na & 32 & na & na & na & na & na & na \\
\hline women & 3 & na & na & 3 & na & 21 & 3 & na & na & 3 & na & 24 \\
\hline $\begin{array}{l}\text { Emergency contra- } \\
\text { ception users }\end{array}$ & na & na & na & 0 & 6 & 6 & na & na & na & na & 7 & 7 \\
\hline Married men & na & 2 & 1 & 3 & na & 15 & na & na & na & na & 7 & 7 \\
\hline Unmarried men & 3 & na & na & 3 & na & 15 & na & na & na & na & 3 & 3 \\
\hline Total & 6 & 8 & 7 & 21 & 6 & 122 & 3 & 9 & 6 & 18 & 17 & 159 \\
\hline
\end{tabular}

*Includes women (in Kampala only) who were in a relationship, whether they were technically married or not. tIn Lucknow, married women were divided according to type of contraceptive used. ҒIn Lucknow, one group of unmarried working women (rather than students) was included to achieve greater socioeconomic diversity. In Kampala, the marital status of the women in this category was relatively ambiguous, although they were more likely to be unmarried than the women in other groups. 
ods and method characteristics, reaction to the concept of pericoital contraception, intent to use pericoital contraception, willingness to pay for the method, and preferred price and source of supply. ${ }^{12}$

Consumer perceptions of the proposed pericoital method were elicited by the following: "Suppose there was a pill that a woman would take up to 24 hours before or after she has sex-so this pill is taken only on days when a woman has sex, instead of every day. For example, a woman could take it 24 hours before sex, or 10 hours before sex, or one hour before sex, or up to 24 hours after sex. It would be intended for women/couples who are not having very frequent sex. What is your impression of that method?" Once participants had shared their impressions of the method and its perceived advantages, they were asked to voice any concerns, questions or perceived method disadvantages. After expressing any reservations, they were prompted to discuss three specific issues: irregular bleeding (given that levonorgestrel is associated with this side effect), method effectiveness (based on currently available data ${ }^{3}$ ) and HIV prevention. First, participants were asked, "If this method caused spotting or irregular bleeding, would women still consider using this? Why or why not?" As a probe for consumers' concerns about method effectiveness, participants were asked, "Considering that this product may be more effective than condoms and less effective than regular birth control pills at preventing pregnancy, how likely are women to consider using this method?" Participants were also asked, "If the method only prevented pregnancy but did not protect against HIV, would women still consider using it? Why or why not?"

In both Lucknow and Kampala, each focus group discussion and interview was conducted by two moderators of the same gender as the participants. In Lucknow, all moderators were Indian and were fluent in both Hindi and English. Moderators in Kampala were fluent in Luganda. Focus group discussions and interviews were conducted in the language (English, Hindi or Luganda) preferred by participants.

Field teams were trained on the purpose of the study, research ethics and use of the guides, and each moderator demonstrated mastery of interviewing, facilitating and note-taking skills prior to data collection. After confirming participants' eligibility, the moderators explained the study purpose and obtained written consent. They stressed the voluntary and confidential nature of the assessment at the time of recruitment and again at the start of each focus group discussion or interview. No name identifiers were recorded during data collection.

The focus group discussions and interviews were audio-recorded and lasted 1-2 hours; each focus group comprised 5-10 individuals. In Lucknow, all focus group discussions and interviews took place in private rented spaces in the community. In Kampala, focus group discussions and interviews with women took place in private settings, usually in a closed room in a family planning clinic or a rented space in the community. Interviews with men in Kampala mainly took place in their home, at the preference of participants; again, privacy was assured.

Data analysis approaches were slightly different across the field teams. In India, the team transcribed the audio files and translated them from the local language, read the transcripts and sorted the information by topic. Once transcripts were compiled, researchers developed themes by identifying similarities and differences among groups. In Uganda, all interviews and focus group discussions conducted in the local language were translated into English. According to the preferences of the highly experienced female moderators in Uganda, notes and audio recordings from women's focus groups and interviews were used to develop expanded field notes, which were used as the basis for analysis; men's interviews were transcribed verbatim. All teams compared data from each focus group discussion and interview with findings from the other discussions to identify themes that resonated across similar groups or among similar individuals, or that were distinct to a particular individual or group. Information coding followed an inductive approach in which codes and themes evolved organically from the transcripts and notes. Teams carried out multiple iterations of data synthesis, interpretation and summarization in both settings, and they implemented quality control procedures during data analysis. Specifically, researchers in the United States independently analyzed transcripts from three focus group discussions in each setting and then compared the findings with those of the field teams in each country to ensure a systematic and replicable approach to data analysis.

The Lucknow Ethics Committee in India, the Institutional Review Boards at Makerere University in Uganda and the Ugandan National Council for Science and Technology granted research ethics approval for the study.

\section{RESULTS}

\section{Perceptions of Pericoital Contraception}

Across population segments and in both country settings, many participants viewed the product favorably, including a large majority in India and a majority in Uganda (especially among young, unmarried women). Positive attributes and advantages of this potential method that emerged in both countries included the convenience of not having to take a daily pill, flexible timing for taking the pill (although perceptions of this varied somewhat by study location and subpopulation), and the potential for discreet use, which was especially appreciated in Uganda. The most prominent concerns that emerged about this method had to do with safety and side effects; in Uganda especially, participants had concerns about the potential effects of the proposed pill-and of hormonal methods generally-on future fertility. Many women did not see potential for irregular bleeding, predicted lower effectiveness relative to oral contraceptives, or lack of HIV protection as likely to discourage their use of the method. Proportionately more men than women in both countries expressed concern about these three issues. 


\section{Freedom from a Daily Pill}

Participants from all categories commented on the convenience of not having to take a daily pill. In nearly every focus group or interview in both countries, women pointed out that pericoital contraception would reduce the daily burden of regular pill use.

"We only have to take this when we have intercourse, not every day. If we take this four times in a month there is no harm."-Married woman, age-group 30-45, Lucknow

"It is so demanding and a burden to take pills day by day, even if you may only expect to have your partner about [nearby] next month. It is so inconveniencing. You feel it is a burden. So you take that [pericoital contraception] to ease your way of life."-Female college student, Kampala

In discussing the convenience of the proposed pericoital pill, a few men and women observed that taking one pill around the time of intercourse would be easier to remember than taking a pill each day, and the connection between the pill and sexual intercourse may serve as a memory trigger.

"You will not forget. When you are going to do the action, you take it."-Married man, aged 49, Kampala

"I would rather take one pill when I know I am going to have sex...than take a pill every day. The other pills you take them every day...this [pericoital contraception] is better. It is like solving forgetfulness.... If you forget, you can take it after."-Female college student, Kampala

"This is good, because we have to take Mala-D [common brand of oral contraceptives in India] daily and this we have to take it once. Because females are very busy, they can forget to take, so this is good."-Female college student, Lucknow

For a few men interviewed in Uganda, the advantage of an occasional pill appeared to be less about convenience than about the improved efficacy associated with better compliance. Because a pericoital pill is less burdensome and easier to remember than regular oral contraceptives, men thought that women would be less likely to miss pills and therefore better protected from pregnancy.

"When you miss [a dose] in the previous type of pills [oral contraceptives], there are chances that you will get pregnant. I think for this one, you may also miss, but it may not occur frequently like the previous one. I do not know how to put it. It is something easy to deal with. The people using it may be more compliant."-Married man, aged 37 , Kampala

\section{Flexibility and Timing}

Another advantage that emerged from all groups of women and men in India, and from some in Uganda, is the flexible timing of taking the pericoital pill. The concept of taking a pill after sex to prevent pregnancy was a novel idea to some women older than 30 in Uganda who had not used emergency contraception.

"Ehh, that [pericoital] pill is a very good one. You might forget and have sex but later you remember... It is very good because I do not think that for these other pills [oral contraceptives], you can have sex and then have her take it afterwards."-Unmarried man, aged 30, Kampala

"Good it does not have a fixed time of taking it. You can take anytime, even after having sex."-Woman, age-group 30-45, Kampala

The novelty and advantage of taking the pill before sex was a stronger theme in India than in Uganda; participant remarks suggested greater awareness of and familiarity with emergency contraception. The ability to take a pill before sex was perceived by participants to be advantageous, reducing the tension associated with unprotected intercourse.

"It is good because other tablets [emergency contraception] you have to take if you have any doubt about pregnancy, but this tablet you can take before 24 hours or after 24 hours of sex, so it is better than those [emergency contraception]."-Female college student, Lucknow

One woman interviewed in Uganda was familiar with the idea of a pill taken before sex, as she takes emergency contraception in anticipation of sexual intercourse:

"Those pills work nicely, they can do whatever you want... Me, most times I use emergency contraception for my part-time [casual partner]. I know I am going to meet the person. Many times I have been using it before, the day before I meet my person."-Emergency contraception user, Kampala

By contrast, the limit on the number of times pericoital pills should be taken within a given month emerged as a theme of concern among many Ugandan women, especially married women. They noted that married women are generally not at liberty to negotiate the number of times they engage in intercourse with their husband. A few Ugandan women also expressed concern about the shorter time frame for using pericoital contraception, relative to the 72-hour window for using emergency contraception.

"The pill will work for people who are just in relationships but for marrieds, I don't think you are going to tell your husband, 'four times only!' Maybe for people in relationships who know, 'I am going to check on [see] him the other weekend.' Not the one who is going to stay with the person day after day and you are going to tell him, 'my dear, I am on the [pericoital] pill, and you know it has to be four times only and we have finished our four times of the month.' It might work for these other people but not for marrieds."-Woman, age-group 20-29, Kampala

"The time limit is also little. The emergency contraception pill gives you at least three days so that you remember your sins. This one is just one day."-Woman, age-group 20-29, Kampala

Many married women in Uganda noted that because they often cannot predict when sexual activity will occur, the pill would be taken more often after sex, rather than in anticipation of sex. One of the men interviewed echoed this reasoning:

"This should be after sex that a woman can take the pill. Because on most occasions, I do not stay with my wife. 
When I am going home to meet her, I cannot even raise her [call her] to tell her, 'now I am coming, remember to take those pills.' At times I can call her and her phone is off. It should be after sex."-Married man aged 27, Kampala

Most female college students and recent graduates in Uganda, however, seemed to feel able to anticipate when they might need pericoital contraception and valued being able to take it before sex. College women in India were not as forthcoming in discussing sexual activity, seldom speaking from a personal perspective.

"I am talking about college girls. You go to visit your boyfriend or whatever, because in most cases when you go you know things will happen, you go prepared. Instead of you being there already, and then after, sometimes you remember... It helps you prepare."-Female college student, Kampala

\section{Discreet Use}

Many women in Kampala remarked that they could take pericoital contraception without the knowledge of their spouse or partner; discretion and the ability to hide method use was also mentioned by a few women in Lucknow. Many Kampala participants felt that since pericoital contraception would consist of only a single dose, they could easily hide it from a spouse who does not support family planning, and they valued being able to use a method surreptitiously.

"It is a secret weapon. For pills, he can easily check because the thing is there. He can easily check in your bag and find the pill there. However this one, you swallow it in the bathroom and clear everything."-Female college student, Kampala

"There are some husbands who do not want family planning; they want you to produce and produce until you are old. This pill you can hide and take after sex without your husband's knowledge."-Woman, age-group 20-29, Kampala

\section{Safety, Side Effects and Future Fertility}

Across subgroups and country settings, many participants (both male and female) spontaneously expressed concern over method safety and possible side effects.

"Won't it destroy our eggs? Won't our children lose sexual appetite? Won't we lose weight? Won't we bleed a lot with huge clots of blood? Won't we grow excessively fat? All family planning methods have side effects."-Woman, age-group 30-45, Kampala

Many women in Uganda, and a few participants in India, voiced unprompted the specific concern that a pericoital pill should not limit one's ability to conceive in the future. Participants also raised fears of compromised fertility related to hormonal method use generally.

"It shouldn't happen that the lady can't get pregnant in future; no side effects like this should be there."-Married woman, age-group 30-45, Lucknow

"Can it affect her chances in the future for producing [reproducing] as a result of overusing it?"-Married man aged 28, Kampala

\section{Irregular Bleeding}

Most married women in India and Uganda expressed minimal concern about irregular bleeding, and some said that bleeding between menstrual cycles was a common side effect of family planning and not problematic. Some also noted that receiving information about this side effect from providers before starting the method would help allay potential concerns about bleeding.

"As it is, the menses get irregular sometimes, so no problem. It happens even if we do not take anything, so we will take it."-Married woman, age-group 20-29, Lucknow

"Bleeding cannot affect use [of a pericoital contraceptive product]...provided the woman is counseled and is aware of this side effect."-Woman, age-group 30-45, Kampala

Young, unmarried women were more concerned about menstrual spotting than married women in Uganda and India, but for different reasons. In India, a few college women observed that if a pericoital pill were to trigger excessive bleeding, the stigma of premarital sexual activity would inhibit girls from seeking advice and limit method appeal.

"If there is much bleeding, girls will get scared. They cannot ask their mother [about the bleeding]."-Female college student, Lucknow

In Uganda, a few women thought that intermittent bleeding could limit method appeal because an irregular menstrual cycle is inconvenient.

"It disorganizes you for those three, four, five days. So that grace period where you are resting and having your nice time, and then this thing [irregular bleeding] comes, it would just disturb you... Period is bad enough. Now something coming in the middle is just not funny. So if it [pericoital contraception] ever had that side effect, people would think twice before using it."-Female college student, Kampala

About half of the Ugandan men interviewed, and most married men in India, also found irregular menstrual bleeding to be undesirable because it would interfere with sexual activity or cause health concerns.

"Most people will lose hope because as I said, oral pills also cause bleeding and abnormal ones [periods]. To me, a man, that one [pericoital contraception] is very inconveniencing because you cannot stay with a woman in the house when she is bleeding. So people will not welcome that one."-Married man aged 27, Kampala

\section{Potential Effectiveness}

Participants were somewhat divided on the importance of method effectiveness. For some Indian women and a few Ugandan women, their willingness to continue with the method may be tied closely to its effectiveness. For some men in India and most of the men interviewed in Uganda, the lower expected effectiveness of a pericoital pill relative to oral contraceptives is a disincentive to use.

"So then it is better to take daily pill, because there will be doubt that it [pericoital contraception] is safe."-Married man, Lucknow

"If it fails, I think they will not like it because it will cause 
confusion in the family first of all. I know you have taken the pill and you come and tell me you are pregnant. 'No, you are lying. That is not my son. That is not my pregnancy. I am not responsible for that.' It will end up causing family havoc. Men will not like that. Even a woman would not like that to happen in her family."-Unmarried man aged 30, Kampala

In one of the focus group discussions, female college students in India considered low effectiveness to be a significant disincentive, remarking that a pericoital pill would be a better method for married women due to the stigma of pregnancy among unmarried women.

"Only married women can take this pill, because even if she becomes pregnant there is no fear. Unmarried cannot take it."-Female college student, Lucknow

Some older women and emergency contraception users in Uganda also expressed concerns about effectiveness.

"If I want to protect myself and I take it, [but] it does not do what it is supposed to do, I end up disappointed. Effectiveness is very important, because it is the real thing you want it to do for you."-Emergency contraception user, Kampala

However, in the Ugandan context, most women were not unduly worried about the effectiveness of pericoital contraception. Most did not strongly indicate that they would refuse to use a pill that was less effective than regular oral contraceptives. Some seemed more excited about the other advantages of the single pill and were willing to try it if it did not have side effects.

"If it is less effective, some people would reject it... If it has not worked for one, then that person may tell others not to use it. But it would not stop people from using it.... Methods can fail, so what matters is convenience. All we need as women is a method that can work and with less side effects and more convenient. Convenience matters."Woman, age-group 30-45, Kampala

\section{Lack of Dual Protection}

Most participants in both countries did not consider lack of HIV protection a barrier to method acceptance and felt it would only be problematic if one were to have multiple partners. Women in Uganda noted that people have been sensitized about HIV and would minimize their risk of infection in other ways (e.g., by knowing their partners' HIV status and choosing appropriate protection). Some Ugandan women observed that women are more concerned about pregnancy than HIV infection. Especially in India, many women and men noted that most currently available modern contraceptives also do not offer protection from HIV.

"You test, and when you find you are both negative, you can use this kind of pill."-Female college student, Kampala

"If you do not know the status of the woman, you have to use [condoms]. But if you know [her status] and you know yours, you can't use condoms. I know my companion is negative and I am negative, there is no need for condoms anymore as long as this method is there." -Unmar- ried man aged 30, Kampala

However, many men in both countries, especially unmarried men in India, as well as a few unmarried women in India, were concerned about the lack of HIV protection. A few women and men in Uganda expressed concerns about the possibility of pericoital pill use replacing condom use and facilitating the spread of HIV. Four in 10 Ugandan men volunteered that they would prefer pericoital contraception over condoms if it were available.

"The rate of AIDS will increase a bit instead of decreasing because people will not practice this protected sex [with condoms]. Most ladies in Uganda, I know they fear pregnancy more than AIDS."-Unmarried man aged 30, Kampala

"The truth is that if this pill is effective, then there is no reason as to why I should wear condoms. This is because I do not feel as good when having sex with my partner when I use condoms. I do not enjoy much."-Married man aged 28, Kampala

A number of the Ugandan men interviewed described contextualized method use in which they would continue using condoms with partners they do not know well or trust, while using pericoital contraception with their spouse or regular partner.

"It is better that we use it [pericoital contraception] with our partners in our homes and not with the extramarital partners because we need to wear condoms for those we meet outside marriage."-Married man aged 25, Kampala

\section{Potential Users}

Participants' perspectives on the appropriate clients for this method varied somewhat across the two country settings. In Uganda, most participants thought that young, unmarried, sexually active women have lifestyles that would align well with pericoital contraceptive use, given that they are motivated to avoid pregnancy and that their coital frequency would likely be appropriate for the method. Many college students readily identified themselves as potential users

"Unmarried women-school girls-because they may meet their boyfriends once a month...they do not want to become pregnant...they will like it very much."-Woman, age-group 30-45, Kampala

"I think it will suit them because most university girls are not married. So in most cases when you are to have sex, I do not think it is on a daily basis, so I think it is suitable."-Female college student, Kampala

In India, diverse potential target audiences for pericoital contraception were identified, including working women, educated women, those aged 25 or older who are not using permanent contraception, women who do not reside with their husbands and unmarried women.

\section{DISCUSSION}

Our qualitative study suggests that in both settings, many women embraced the idea of a female-controlled method that would be easier than taking a daily pill, would offer 
flexibility in timing and could be taken without a partner's knowledge. A theme that the team heard repeatedly and resoundingly was that the daily dosage schedule for oral contraceptives is challenging and feels bothersome. At the same time, many of the participants who were receptive to the proposed method also raised concerns about it, specifically, about the nature and severity of potential side effects and, for married Ugandan women in particular, use among those unable to negotiate sexual frequency.

Key differences emerged between the two settings that reflect broader differences in terms of family planning and cultural norms. Injectable contraception is the most popular contraceptive method in Uganda; ${ }^{11}$ use of this method is easily hidden from partners who may be opposed to contraception. Therefore, it is perhaps not surprising that discretion emerged as an especially prominent advantage of pericoital contraception among our female sample in Uganda. By contrast, effectiveness emerged as a greater concern for women in Lucknow, a setting in which sterilization dominates the method mix $^{10}$ and where unintended pregnancy among unmarried women may have serious social consequences.

Pericoital contraception was particularly appealing to young, unmarried female participants in Uganda. Premarital sexual activity is fairly common in Uganda, with about one in four adolescent women aged 15-19 and nearly half (45\%) of adolescent men reporting that they are sexually active but not yet married. ${ }^{13}$ Many unmarried women feel inhibited to seek family planning from clinics and tend to use contraceptives inconsistently. ${ }^{14}$

Unmarried women were also identified as a possible audience in India, but premarital sexual activity remains highly stigmatized there, and it is therefore difficult to estimate the share of unmarried women needing contraceptive services. Though there have been very few studies of premarital sexual activity in India, a recent survey in Pune District found that $10 \%$ of young women were sexually active before marriage. ${ }^{15}$ A relatively small share of young Indian women may be exposed to pregnancy risk, but for those who are sexually active, condom use is quite rare-a recent study found that only $7 \%$ of sexually active young women reported that they had ever used a condom. ${ }^{16}$ Because of the stigma associated with premarital sexual activity, offering pericoital contraception via pharmacies may provide a reasonable alternative for young women who find clinic-based family planning services unreceptive and do not feel comfortable purchasing condoms or insisting on condom use by their partners. Moreover, studies suggest that the daily schedule for oral contraceptives is challenging for adolescent women. ${ }^{13,17}$ Pericoital contraception may be appropriate for young unmarried women who have periodic sex and struggle with the daily oral contraceptive schedule.

Unmarried women are not the only potential targets for this method. There is a large population of women for whom a pericoital pill could be appropriate, based on coital frequency. An estimated 63\% of currently married women in Uttar Pradesh, India, and 45\% of married and sexually experienced unmarried women in Uganda have sex about six times or less in a given month and more than twice in six months. ${ }^{18}$ A recent study from the United States found that among married women aged 30-49, more than two-thirds had sex at least a few times in a year, but no more often than once a week; the same was true among 59\% of women aged 25-29. ${ }^{19}$ For women who are having sex once a week or once a month, taking a daily pill may feel impractical and burdensome. Analyses to identify the extent to which women who have sex infrequently use contraceptive methods, the methods they use, and whether they are using them effectively and consistently should inform the introduction of pericoital contraception. Subsequent research should also provide further information on the appeal of a pericoital pill among women having more frequent sex and their potential use of the method.

The receptivity of Ugandan and Indian consumers to pericoital contraception suggests that many of the features of this method align with women's contraceptive preferences. Receptivity toward the method among women in our sample is consistent with the results of a recent study that found pericoital pills are rated very favorably, relative to other methods, when methods are compared on the basis of their characteristics. ${ }^{20}$ The authors found that an over-the-counter pericoital pill has $68 \%$ of the method features that women consider extremely important and is a closer match to women's preferences than any existing method, except for over-the-counter oral contraceptives, which have $71 \%$ of desired features. Naturally, methods that reflect women's expressed preferences for what they value most should be given high priority as new contraceptive technologies are developed.

Most married women in our sample did not perceive that intermittent bleeding would prevent them from using pericoital contraception, but a few younger, unmarried women, as well as men, expressed reservations. Studies of adolescents' experiences with oral contraceptives have found that breakthrough bleeding or amenorrhea is a key cause of discontinuation because irregularity is inconvenient and provokes anxiety about pregnancy and future fertility. ${ }^{21}$ Breakthrough bleeding may also create challenges for pregnancy detection, particularly for women using pericoital contraceptives multiple times during the menstrual cycle. Moreover, dual use of a pericoital pill with periodic abstinence would not be feasible because intermittent bleeding would make identifying the fertile period difficult.

Few women in either setting reported that they would be discouraged from using pericoital contraception due to the lack of HIV protection. The opinions of men were more variable; some indicated a preference for pericoital contraception over condoms, while others indicated an intention to continue condom use with new or extramarital partners. Some men anticipated that preference for pericoital contraception over condoms (depending on the partner) might make the proposed method problematic 
from a public health standpoint, but it may also simply reflect a general reluctance among men to use condoms. Nonetheless, particularly in places where HIV infection rates are high, reinforcing messages about HIV risk for pericoital pill users, as well as for users of other hormonal methods and IUDs, will be important.

The perspective of potential consumers is but half the dynamic in assessing the appeal of and potential demand for a new method. Efforts to introduce pericoital contraception should also be guided by the views of family planning providers and policymakers to identify enabling and inhibiting factors for method introduction. ${ }^{12}$

\section{Study Limitations}

This study is limited in several ways. The sample was purposive, and the opinions of participants may not be representative. In particular, the small samples of emergency contraception users and men limit what we can conclude about the views of these groups. There were also a number of country-specific challenges. In India, the stigma associated with premarital sexual activity seemed to hinder young women from discussing contraception in a small group. In Uganda, the field team faced difficulty identifying emergency contraception users and higher-income women for inclusion in the study. They were also unable to select participants according to family planning use patterns, which may have created less homogeneous groups than would have been desirable. In both countries, we presented pericoital contraception to participants as intended for women who have infrequent sex, given the high level of unmet need in this population. By doing so, we may have created another study limitation: Respondents may have been unduly concerned that some women might use the method more frequently. Finally, this study queried consumers about how women and men expect to use a hypothetical method; research has shown that perceived method appeal may differ from actual practice and perceptions. ${ }^{12}$

\section{REFERENCES}

1. Sedgh G et al., Women with an unmet need for contraception in developing countries and their reasons for not using a method, Occasional Report, New York: Guttmacher Institute, 2007, No. 37.

2. Darroch JE, Sedgh G and Ball H, Contraceptive Technologies: Responding to Women's Needs, New York: Guttmacher Institute, 2011.

3. Halpern V, Raymond EG and Lopez LM, Repeated use of preand postcoital hormonal contraception for prevention of pregnancy, Cochrane Database of Systematic Reviews, 2010, Issue 1, No. CD007595.

4. Keesbury J, Morgan G and Owino B, Is repeat use of emergency contraception common among pharmacy clients? Evidence from Kenya, Contraception, 2011, 83(4):346-351.

5. Lerkiatbundit S and Reanmongkol W, Use of $0.75 \mathrm{mg}$ levonorgestrel for postcoital contraception in Thailand, Journal of Clinical Pharmacy and Therapeutics, 2000, 25(3):185-190.

6. Opoku B, Contraceptive use among "at-risk" women in a metropolitan area in Ghana, Acta Obstetricia et Gynecologica Scandinavica, 2010, 89(8):1105-1107.

7. Chin-Quee D, Repeat use of emergency contraceptive pills: a study of urban women in Kenya and Nigeria, paper presented at the annual meeting of the American Public Health Association, San Francisco, CA, USA, Oct. 27-31, 2012
8. Teixeira M et al., Representations and uses of emergency contraception in West Africa. A social anthropological reading of a northern medicinal product, Social Science E Medicine, 2012, 75(1):148-155.

9. World Health Organization (WHO), Fact sheet on the safety of levonorgestrel-alone emergency contraceptive pills, Geneva: WHO, 2010.

10. International Institute for Population Sciences (IIPS), District Level Household and Facility Survey (DLHS-3), 2007-08: India, Mumbai: IIPS, 2010

11. Uganda Bureau of Statistics (UBOS) and ICF International, Uganda Demographic and Health Survey 2011, Kampala, Uganda: UBOS; and Calverton, MD, USA: ICF International, 2012

12. Heise L, Beyond acceptability: reorienting research on contraceptive choice, in: Sundari Ravindran TK, Berer M and Cottingham J, eds., Beyond Acceptability: Users' Perspective on Contraception, London: Reproductive Health Matters, 1997, pp. 6-14.

13. Darabi L et al., Protecting the Next Generation in Uganda: New Evidence on Adolescent Sexual and Reproductive Health Needs, New York: Guttmacher Institute, 2008.

14. Nalwadda G et al., Persistent high fertility in Uganda: young people recount obstacles and enabling factors to use of contraceptives, BMC Public Health, 2010, doi: 10.1186/1471-2458-10-530, accessed Nov. 3, 2013.

15. Alexander $M$ et al., Romance and sex: pre-marital partnership formation among young women and men, Pune district, India Reproductive Health Matters, 2006, 14(28):144-155.

16. Santhya KG, Acharya R and Jejeebhoy SJ, Condom use before marriage and its correlates: evidence from India, International Perspectives on Sexual and Reproductive Health, 2011, 37(4):170-180.

17. Woods JL et al., Patterns of oral contraceptive pill-taking and condom use among adolescent contraceptive pill users, Journal of Adolescent Health, 2006, 39(3):381-387.

18. Winfrey B, Futures Institute, special tabulations of data from the Uttar Pradesh and Uganda Demographic and Health Surveys.

19. Herbenick D et al., Sexual behavior in the United States: results from a national probability sample of men and women ages 14-94, Journal of Sexual Medicine, 2010, 7(Suppl. 5):255-265.

20. Lessard LN et al., Contraceptive features preferred by women at high risk of unintended pregnancy, Perspectives on Sexual and Reproductive Health, 2012, 44(3):194-200.

21. Clark LR, Will the pill make me sterile? Addressing reproductive health concerns and strategies to improve adherence to hormonal contraceptive regimens in adolescent girls, Journal of Pediatric and Adolescent Gynecology, 2001, 14(4):153-162.

\section{RESUMEN}

Contexto: Hay estudios que sugieren que, en algunos países, las mujeres han adoptado las píldoras de anticoncepción de emergencia como método rutinario de planificación familiar. Esta práctica indica que puede haber una demanda latente para una pildora anticonceptiva pericoital, etiquetada y comercializada para su uso como método anticonceptivo habitual, que se tome solamente cuando una mujer tenga una relación sexual.

Métodos: Para comprender el atractivo y el mercado potencial de una píldora anticonceptiva pericoital, se condujeron 39 grupos focales y 23 entrevistas en profundidad con mujeres y hombres en Kampala (Uganda) y Lucknow (Uttar Pradesh, India). Un total de 281 individuos participaron en este estudio cualitativo.

Resultados: En general, las mujeres apoyaron la idea de un método controlado por la mujer, más fácil usar que una píldora anticonceptiva oral diaria, y que podría tomarse tanto 
antes como después de la relación sexual. En Uganda, especialmente, las mujeres aprobaron que el método pueda tomarse sin el conocimiento de la pareja. Aunque todavía no se conoce cuáles son los efectos secundarios de este método, las mujeres expresaron preocupaciones sobre el grado y la naturaleza de los efectos secundarios potenciales.

Conclusiones: Los resultados sugieren que una píldora anticonceptiva pericoital sería bien recibida por las consumidoras de los dos países estudiados. Si su eficacia y los efectos secundarios son aceptables, una píldora anticonceptiva pericoital podría responder a la demanda de un método anticonceptivo controlado por la mujer, discreto, relacionado con la relación sexual, especialmente entre las mujeres que no tienen relaciones sexuales con mucha frecuencia.

\section{RÉSUMÉ}

Contexte: Les études laissent entendre que les femmes de certains pays ont adopté la contraception d'urgence comme méthode régulière de planification familiale. Cette pratique est peut-être signe d'une demande latente d'une pilule péricoïtale, que la femme ne prendrait qu'en cas de rapports sexuels et qui serait étiquetée et commercialisée comme méthode contraceptive ordinaire.
Méthodes: Dans le but de cerner l'attrait et le marché potentiel d'une pilule contraceptive péricoitale, 39 groupes de discussion et 23 entretiens en profondeur ont été organisés avec des femmes et des hommes de Kampala (Ouganda) et de Lucknow (Uttar Pradesh, Inde). Au total, 281 personnes ont participé à cette étude qualitative.

Résultats: De manière générale, les femmes embrassent l'idée d'une méthode féminine plus simple que la pilule journalière et qui pourrait être prise avant ou après les rapports sexuels. Les Ougandaises en particulier approuvent le fait que la méthode pourrait être pratiquée à l'insu du partenaire. Bien que l'étendue des effets secondaires de cette méthode ne soit pas encore connue, les femmes expriment certaines réserves quant au niveau et à la nature des effets secondaires potentiels.

Conclusions: Les résultats laissent entendre qu'une pilule contraceptive péricoitale serait bien reçue sur le marché des deux contextes considérés. Si son efficacité et ses effets secondaires sont acceptables, la pilule péricoitale pourrait combler une lacune en termes de contraception féminine discrète dépendante de l'acte sexuel, en particulier pour les femmes dont l'activité sexuelle n'est guère fréquente.

Author contact: jcover@path.org 